\title{
Effect of Principals' Emotional Intelligence on Schools' Academic Performance: A Survey of Nepali Institutional Schools
}

\author{
- Jiban Khadka, PhD \\ Associate Professor, Nepal Open University
}

\begin{abstract}
Emotional intelligence (EI) has become a central concern to carry out any study on leadership and its effectiveness in schools and other institutions. This study was intended to investigate the effect of the principals' EI on the academic performance of Nepali institutional schools. A sample of 121 principals and 491 teachers from the schools of three districts of Nepal (Jhapa, Kathmandu and Kaski) was drawn following cluster sampling method. The data were collected through Emotional Intelligence Survey Questionnaire. From the data analysis using non-parametric statistical measures, it was revealed that the principals had higher level of emotional intelligence irrespective of their demographic characteristics. The findings indicated that the schools' principals were emotionally intelligent and effective in maintaining the schools' academic performance. The findings can lead to conclude that leadership performance can be enhanced in schools by developing emotional intelligence in the principals' leadership behaviour.
\end{abstract}

Keywords/terms: Emotional intelligence, leadership effectiveness, demographic characteristics, academic performance

\section{Introduction}

In recent trend of researches, emotional intelligence (EI) has become a central concern to carry out any study on leadership and its effectiveness in schools and other institutions. It is a highly instrumental human attribute, and also a strong predictor of job performance and leadership effectiveness (Kumar, 2014). In this connection, Goleman (1998, cited by Weinberger, 2003, p. 1151) writes: "The most effective leaders are alike in one crucial way; they all have a high degree of what has come to be known as emotional intelligence". With this consideration, the principals of Nepali Institutional (Private) schools can be supposed to have better understanding of EI and handle it effectively as the schools are successful in terms of students' learning achievements as compared to community (Public) schools. 
Effect of Principals' Emotional Intelligence on Schools' Academic Performance...

The principals have to carry out the regular instructional and noninstructional activities in the schools. In the schools, besides the functions, duties and powers stated in the Education Act 1971 and Regulations 2016, different responsibilities are assigned or delegated by the school's management committee and board of directors. All these academic and administrative roles and functions usually make the principal's job hectic. For handling such a situation, principals should have the knowledge and skills to know others, themselves, and manage the situation accordingly. For this, interpersonal and intrapersonal skills are essential. In these circumstances, it is relevant to investigate the emotional intelligence of the school principals in relation to their school performance, considering whether EI has been an effective factor to enhance school performance.

\section{Research questions}

To handle school management, it is essential for a principal to have effective practice of leadership so that $\mathrm{s} / \mathrm{he}$ can demonstrate better performance of school. Emotional intelligence is one of the factors to run school management. But, it is still not clear as regards the status of emotional intelligence of the principals in the Nepalese schools. Research on emotional intelligence, and its effect on schools' academic performance is under researched in the context of Nepali institutional schools in particular. Therefore, it is essential to address this issue in the context of Nepali institutional schools. This study was intended to address the following research questions:

1. What is the status of the institutional school principals' emotional intelligence?

2. To what extent does emotional intelligence of the principals explain the schools' academic performance?

\section{Research methods}

This study was intended to investigate the principals' EI introduced by Goleman (1998, referred to by Weinberger, 2003) as it seeks the emotional behaviours such as values, interpersonal skills, communication skills, confidence, and creativity skills. Further, the academic performance of the schools was examined considering whether the performance was explained by the principals' EI. This study was carried out in quantitative research design, and it was associated with what Creswell and Plano Clark (2011) say "post-positivist philosophical assumptions" with the belief of reality that can 
be empirically measured, but testing and re-testing is necessary. The level of EI in principals can be assessed in objective way that is the reality for a time. However, confirmation and re-confirmation on the issue is essential.

In this study, for generalizable findings, attitude from a large size sample of teachers towards the principals' emotional intelligence was assessed by a survey done 'at one point in time' (Creswell, 2013). The target population for sampling frame of this survey was divided into three regions: Eastern, Central and Western. From the population of the institutional schools' principals and teachers of three districts (Jhapa, Kathmandu and Kaski), Cochran's (1977) formula was used to determine the sample size of 121 principals and 491 teachers from Nepali institutional schools, and the sample was drawn following the cluster sampling method. The data from the sample of principals and teachers were collected through the survey questionnaire: Emotional Intelligence Survey Questionnaire (EISQ).

The questionnaire designed by Rahim and Psenicka (2002) after seeking permission was used to collect the data about EI from school principals. However, in the questionnaire, there were many variables that could not be contextualized in Nepal. Therefore, the researcher reviewed other sources such as Harvard Business Review (2004) and Coaching Leaders (2008) to enrich its contents. The process of "translation-back-translation" (Harkness, 2003) was used to prepare the questionnaire in Nepali version. The questionnaire was prepared in Likert scale that was ranged from 'strongly disagree' to 'strongly agree'. The values in the scale were: 1 for 'strongly disagree', 2 for 'disagree', 3 for 'undecided', 4 for 'agree', and 5 for 'strongly agree'. It consisted of 25 items for assessing the components of Goleman's EI (self-awareness, self-regulation, motivation, empathy and social skills), and modified in rater (teacher) version - as the teachers were the primary units of data analysis.

Reliability of the items in the questionnaire was established by Cronbach's alpha after administrating a pilot test in ten schools of Kathmandu district, and the validity was ensured by seeking experts' opinions. The percentage of teachers and ranks were used as descriptive statistics; and Spearman's rank correlation, Mann Whitney test, Kruskal Wallis test and Logistic regression were employed as inferential statistical for analyzing the data. Ethical concerns of this study such as informed consent, confidentiality, anonymity, etc. were considered while undertaking the entire study. The findings of this study are limited to the responses of teachers as the teachers are unit of analysis of this study. 
Effect of Principals' Emotional Intelligence on Schools' Academic Performance...

\section{Literature review}

Emotional intelligence is a topic of popular concern in the field of leadership development. It is empirically justified as an effective predictor of leadership ability and job performance, and linked with the success of a school organization (Shipley and others, 2010). It is concerns the capability of a person to understand his or her own and others' emotions, and manage the situation tactfully. It is simply said to be a cognitive understanding of emotions such as six universal emotions (anger, fear, sadness, happiness, disgust, and surprise) and many others as listed by Assanova and McGuire (2009), McPheat (2010), and Singh (2003). Assanova and McGuire (2009) explain that people perceive or feel their surroundings or phenomena in different emotional ways and stimulate or respond to them in their own ways. These emotional activities distinguish an individual from others. It exerts influence on making decision rationally, and enhances work performance at the workplace. Some of these leadership qualities can be developed through training or by creating conducive environment (Singh, 2003).

In the late $20^{\text {th }}$ century, Daniel Goleman (1995) developed the mixed model of emotional intelligence that concerns with work effectiveness or work performance (Cherniss and Goleman, 2001). Goleman's EI is considered to review in the context, as the intent of this study was to examine EI, which is revealed by past studies as a predictor for effectiveness of schools' performance.

\section{Goleman's mixed model of emotional intelligence}

In school environment, the principals have to act as a pivotal role. They have to deal with various types of people. They have responsibility of how to achieve schools' performance better. They need to display emotionally intelligent behaviors. Goleman (1998, referred to by Cherniss and Goleman, 2001) defines EI as a learned capability that results in outstanding performance at work. It is defined as the combination of emotional and social competencies. It interplays between affective domain (perceiving and feeling) and cognitive domain (thinking). It emerged as a subject of study in the 1990s in the field of psychology (Northouse, 2010). As stated by Goleman (2004), emotional intelligence comprises five components: selfawareness, self-regulation, motivation, empathy and social skills. The first component is 'self-awareness' that concerns with knowing oneself or knowing own emotions. The second component 'self-regulation' means the 
Effect of Principals' Emotional Intelligence on Schools' Academic Performance...

ability to regulate or operate own emotional behaviours. The third is 'motivation' that inspires someone to do something for its own sake. 'Empathy', the fourth component, is the ability of understanding others' emotional state. In addition, the last is 'social skill' that is concerned with developing or maintaining relation among people to move towards the desired directions. Based on the nature of EI-components, these five components can be categorized into two groups. The first group includes the 'self-management' skills which are: self-awareness, self-regulation and motivation; and the second group includes relationship skills which are empathy and social skills (Goleman, 2004).

Figure 1: Goleman's mixed model of emotional intelligence

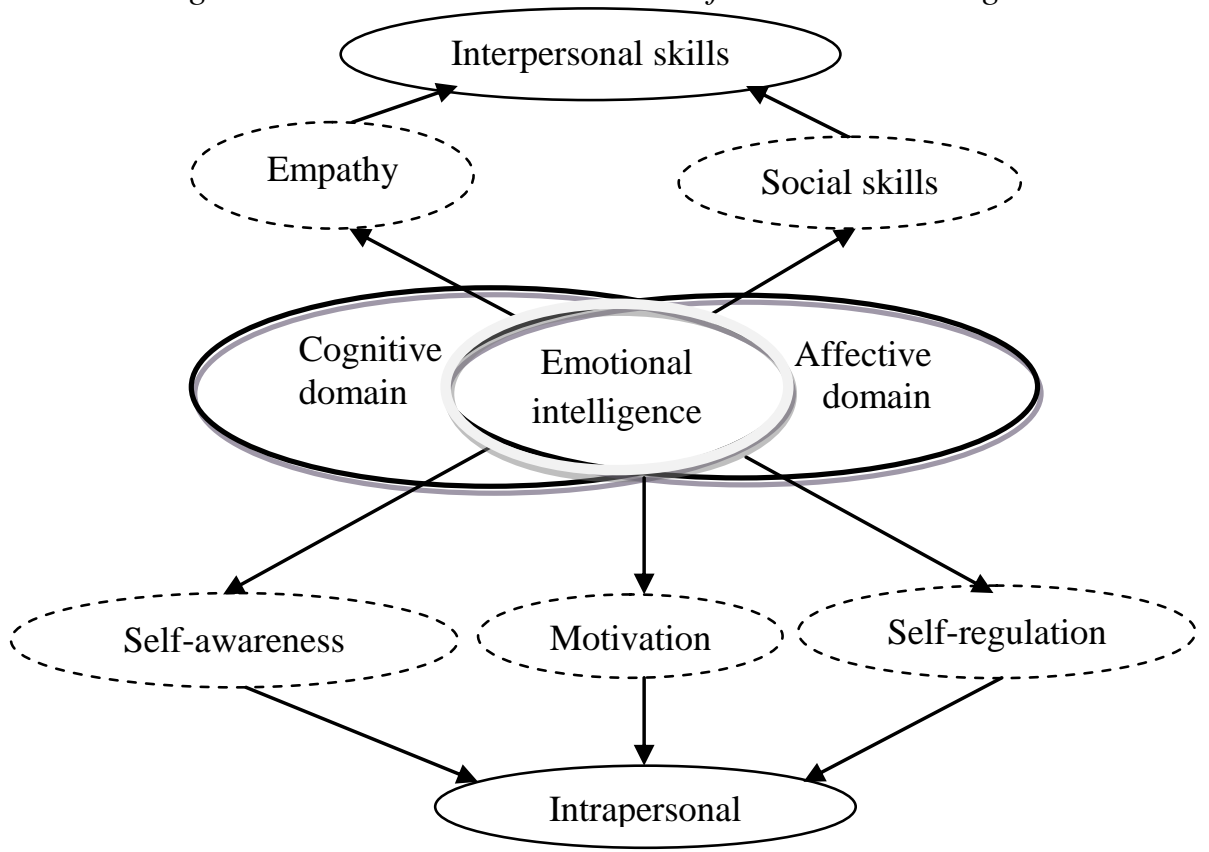

Source: adapted from Goleman (2004), and Cherniss and Goleman (2001)

While reviewing the five components of EI, as shown in figure 1, three components of EI (self-awareness, self-regulation and motivation) are grouped into intrapersonal skills as the competency depends on an individual knowledge and skills, whereas other two components (empathy and social skills) into interpersonal skills. In overall composition of EI, it is the combination of two domains which are 'cognitive' and 'affective'. Hence, 
the concern as to how a person rationally deals with the people is related to cognitive skills, and the concern as to what feeling or emotional behavior is exhibited in front of people is related to affective domain. Both subdomains collectively exhibit a leader's emotional behavior.

The EI of an organizational leader is identified as an effective factor for good performance of organizations. It has an important role both inside and outside the organization (Northouse, 2013; Assanova and McGuire, 2009), and is linked to the achievement of organizational goals (Hartog and others, 1997). Ying and Tzu Ting (2012) revealed that EI was taken as having positive and significant impact on leadership outcomes in the higher education industry in Malaysia (Cook, 2006). Farahbakhsh (2012) stated a positive and significant relationship between emotional intelligence and quality of work life of the principals of the schools of Khorramabad. A study of the managers of banking sector in Iran revealed that EI positively and significantly contributed to the managers' job performance (Shahhosseini and others, 2013). Labbaf and others (2011) found significant positive impact of EI on education officials and Library assistants in Isfahan University that would contribute to the dimensions of a learning organization. Shahzad and others (2011) found a partially positive relation between the EI components and employee's performance among the telecom employees in Pakistan. Thus, EI is found effective in the leadership performance in varieties of institutions. Based on these research findings, the researcher was led to make this statement as a research hypothesis: Principals with high level of EI are more likely to achieve better performance in schools.

\section{Data analysis}

First, the data were collected through survey questionnaire EISQ and a list for principals' demographic characteristics. Descriptive statistics (the percentage of 491 teachers who responded to the questionnaire) was basically used to describe the characteristics of data (Hariri, 2011). As the data were collected through Likert scale questionnaires, the scales were treated as ordinal data, and analyzed using non-parametric measures (Cohen and others, 2007). The internal consistency within the items of questionnaire was 0.901 assessed by Cronbach's alpha, which was closer to the alpha value of pilot study. It showed high level of consistency in the teachers' responses against the rating scale towards their principals' emotional intelligence.

In this study, two-stage analysis process, as stated in Albaum (1997), was employed to measure the variables although the data were collected at one point in time. In the first stage, the aggregate percentage on the stated three 
categories (disagreement, undecided and agreement) were computed that would measure the direction of teachers' responses. In the second stage, the percentage on 'agree' or 'disagree' with the statement was calculated, and that was considered the measure of the intensity of responses.

\section{Principals' emotional intelligence}

In this section, Goleman's EI of the principals and its five components (selfawareness, self-regulation, motivation, empathy and social skills) are analyzed. The detailed statistical results of EI as rated by the teachers are presented in table 1.

Table 1: Descriptive statistics of emotional intelligence of principals

$\begin{array}{lccc}\text { EI components } & \text { Agreement (\%) } & \text { Disagreement (\%) } & \text { Undecided (\%) } \\ \text { Full scale EI } & 74.3 & 7.0 & 18.7 \\ \text { EI-components } & & & \\ \text { Self-awareness } & 76.4 & 6.3 & 17.3 \\ \text { Self-regulation } & 68.8 & 9.7 & 21.5 \\ \text { Motivation } & 75.2 & 6.6 & 18.2 \\ \text { Empathy } & 72.6 & 7.7 & 19.7 \\ \text { Social skills } & 74.9 & 7.3 & 17.8\end{array}$

From the statistical results presented in table 1, we know that the principals had higher level of emotional intelligence. In the overall rating of teachers, the intensity was $42.3 \%$ on the scale "agree" and $32 \%$ on "strongly agree". A low number of teachers disagreed on the statements that the principals had high level of EI. Out of five components of emotional intelligence, a high number of the teachers agreed that their principals had higher level of each component of EI. Even the least number of respondents represented more than two-third of the teachers who rated their principals as having higher level of emotional intelligence on self-regulation. However, $21.5 \%$ of the teachers were undecided whether their principals had high or low level of self-regulation. About $70 \%$ to $75 \%$ of the teachers rated their principals as having high level of other components of EI: motivation, empathy and social skills.

Further, the survey data was analyzed based on the five demographic characteristics of principals (gender, age, experience, qualification and training status). The descriptive statistics and inferential statistics about the principals' emotional intelligence across their demographic characteristics are presented in table 2 . 
Effect of Principals' Emotional Intelligence on Schools' Academic Performance...

Table 2: Emotional intelligence across the demographic characteristics of principals

\begin{tabular}{|c|c|c|c|c|}
\hline \multicolumn{2}{|l|}{$\begin{array}{l}\text { Demographic } \\
\text { Characteristics }\end{array}$} & \multirow{2}{*}{$\begin{array}{l}\text { Mean } \\
\text { Ranks } \\
245.37\end{array}$} & \multirow{2}{*}{$\begin{array}{l}\text { Asymp. } \\
\text { Sig. } \\
\text { (2-tailed) } \\
.725\end{array}$} & \multirow{2}{*}{$\begin{array}{l}\text { Inferential } \\
\text { Statistics } \\
\text { Mann Whitney U } \\
\text { Test }\end{array}$} \\
\hline Gender & $\begin{array}{l}\text { Male } \\
\text { Female }\end{array}$ & & & \\
\hline Age & $\begin{array}{l}25-35 \text { years } \\
36-45 \text { years } \\
\text { Above } 45 \text { years }\end{array}$ & $\begin{array}{l}241.40 \\
247.20 \\
249.58\end{array}$ & .892 & $\begin{array}{l}\text { Kruskal Wallis H } \\
\text { Test }\end{array}$ \\
\hline Experience & $\begin{array}{l}\text { Less than } 5 \\
\text { years } \\
5-14 \text { years } \\
15-20 \text { years } \\
\text { Above } 20 \text { years }\end{array}$ & $\begin{array}{l}233.09 \\
230.54 \\
267.85 \\
276.67\end{array}$ & .034 & $\begin{array}{l}\text { Kruskal Wallis H } \\
\text { Test }\end{array}$ \\
\hline Qualification & $\begin{array}{l}\text { Bachelor } \\
\text { Above } \\
\text { Bachelor }\end{array}$ & $\begin{array}{l}255.37 \\
244.75\end{array}$ & .539 & $\begin{array}{l}\text { Mann Whitney U } \\
\text { Test }\end{array}$ \\
\hline $\begin{array}{l}\text { Training } \\
\text { Status }\end{array}$ & $\begin{array}{l}\text { Trained } \\
\text { Untrained }\end{array}$ & $\begin{array}{l}245.83 \\
250.44\end{array}$ & .800 & $\begin{array}{l}\text { Mann Whitney U } \\
\text { Test }\end{array}$ \\
\hline
\end{tabular}

There was no statistically significant difference on emotional intelligence across the gender, age, qualification and training status of the principals as the $\mathrm{P}$ value $(=.725, .892, .539, .800)$ were greater than the level of significance $(=$ $.05)$. However, the respondent teachers rated the female principals at higher level of rank in emotional intelligence in comparison to male principals - as the mean rank of female principals $(=257.22)$ was higher than the mean rank of male principals $(=244.37)$. Similarly, the principals with the qualification of Bachelor's level (mean rank $=255.37$ ) and untrained teachers (mean rank $=$ 244.75) were ranked at higher level of emotional intelligence. The mean ranks yielded from Kruskal Wallis $\mathrm{H}$ test towards the principals' emotional intelligence were in the order of their ages; so the higher the age of principals the higher the rank of emotional intelligence (mean ranks: $241.40<247.20<$ 249.58 age: $25-35<36-45$ < above 45 years).

Regarding the rating scale towards the emotional intelligence of principals based on their experience, the respective mean ranks of principals' emotional intelligence were not in the linear order of their experience level. However, the principals' emotional intelligence was higher as the experience was 
longer. The principals who had experience of above 14 years had higher level of emotional intelligence (mean ranks $=267.85$ and 276.67 in the respective groups of $15-20$ and above 20 years) than those principals who had experience up to 14 years (mean ranks $=233.09$ and 230.54 in the respective groups of principals with experience less than five years and 5-14 years). The Kruskal Wallis $\mathrm{H}$ test also showed that there was significant difference on emotional intelligence across the experience years of the principals as the $\mathrm{P}$ value $(=.034)$ was less than $\alpha$ value $(=.05)$. But, Bonferroni post hoc test used to identify the significant difference between two groups of principals with regard to their experience did not show significant difference across any two groups of principals based on their experience, as the $\mathrm{P}$ values $(=1.000, .941, .283, .256, .073)$ were greater than $\alpha$ value (=.05). Therefore, it did not signify that the emotional intelligence of principals differed from the experiences of the principals.

\section{Academic performance of Nepali institutional schools}

For analysis of schools' academic performance, the academic performance of sample schools was taken; and it was assessed from School Evaluation Method (SEM). As stated in the documents, the average academic performance in terms of SLC results of three consecutive years is presented below:

Table 3: Average value of sample schools and meritorious schools

\begin{tabular}{lccccc}
\hline Years & \multicolumn{2}{c}{ Average SEM value of sample schools } & & \multicolumn{2}{c}{ National meritorious SEM value } \\
\cline { 2 - 3 } \cline { 5 - 6 } & Highest & Lowest & & Highest & Lowest \\
\hline Average & 46.99 & -2.25 & & 48.99 & 30.07 \\
\hline
\end{tabular}

Table 3 shows that the simple average SEM value of sample schools ranged from -2.25 to 46.99 . About $86 \%$ of the sample schools had SEM value more than the least average SEM value of national meritorious schools. The highest average SEM value was closer to the highest SEM value of meritorious schools.

Despite the successful result on average, some schools are in line to improve the existing level of academic performance as their average least SEM value is -2.25 - which is far below than the least SEM average value $(=30.07)$ of national meritorious schools. However, these extreme cases do not represent the whole statistical results as the ranks were used in computation. In overall observation, the evidence indicated that the institutional sample schools are academically high performing institutions. 
Effect of Principals' Emotional Intelligence on Schools' Academic Performance...

\section{Effect of principals' EI on schools' academic performance}

The binary logistic regression model was used to examine the effect of principals' EI on school performance. The results so obtained from binary logistic regression model were as tabulated below.

Table 4: Model summary

\begin{tabular}{lccc}
\hline Step & $-2 \log$ likelihood & $\begin{array}{c}\text { Cox and snell R } \\
\text { square }\end{array}$ & Nagelkerke R square \\
\hline 1 & $259.881^{\mathrm{a}}$ & .061 & .107 \\
\hline
\end{tabular}

From table 4, the independent variable EI and demographic characteristics reduced the $-2 \log$ likelihood statistics to 259.881 . The table shows that the value of Nagelkerke $\mathrm{R}$ square was .107. This did not indicate strong predictability power of the logistic regression model, that means $10.7 \%$ of the variation in the dependent variable schools' academic performance (SEM values) had been explained by the considered independent variables (covariates).

Table 5: Variables in the equation

\begin{tabular}{lllllll}
\hline & B & S.E. & Wald & Df & Sig. & Exp(B) \\
\hline EI & 1.420 & .355 & 15.955 & 1 & .000 & 4.136 \\
Gender & .762 & .644 & 1.399 & 1 & .237 & 2.143 \\
Age & -.466 & .403 & 1.341 & 1 & .247 & .627 \\
Experience & .183 & .398 & .212 & 1 & .645 & 1.201 \\
Qualification & .406 & .430 & .892 & 1 & .345 & 1.500 \\
Training & -.797 & .519 & 2.359 & 1 & .125 & .451 \\
Status & & & & & & \\
Constant & 1.213 & .680 & 3.179 & 1 & .075 & 3.363 \\
\hline
\end{tabular}

From the statistical results presented in the table 5, the principals with high level of EI were more likely to achieve better performance. Compared to those principals with lower level of EI, the principals with higher level of EI were about four $[\operatorname{Exp}(B)=4.136]$ times more likely to achieve SEM value. The statistical results showed that the hypothesis Principals with high level of EI are more likely to achieve better performance in schools was statistically retained.

Regarding the effects of other demographic characteristics as control variables, all the demographic characteristics including gender, age, experience, qualification and training status of the principals had no 
Effect of Principals' Emotional Intelligence on Schools' Academic Performance...

significant effect on the schools' academic performance as $\mathrm{P}$ values were greater than the level of significance $(=.05)$.

\section{Findings and discussion}

In the concern of the research question, the principals as rated by their teachers were more emotional intelligent leaders. They had relatively high degree of self-awareness and inspirational motivation. EI of the principals was not significantly different across gender; and this finding is consistent with what Cook (2006) and Kumar and Muniandy (2012) contend. However, the findings, in case of gender, contradicts the findings of Adlakha (2014) and Grunes (2011) that found significant difference between leaders' EI and gender. The study of Adlakha (2014) found that male teachers had higher level of EI than female teachers, whereas the study of Grunes (2011) concluded that the female principals had higher level of EI than male principals. The finding in relation to EI of the principals across their age is supported by the finding of Cook (2006), but contradicts with many researchers like Adlakha (2014), Fariselli and others (2006), Barbuto and others (2007), and Kumar and Muniandy (2012). Their studies found that increase in the age of leaders leads to significant rise in their emotional intelligence, which contradicts the findings of this study. However, descriptive statistics of this study showed that teachers rated those principals' EI at higher level who were older in age, and had longer experience. Regarding EI of the principals across their years of experience, the result is consistent with the findings of Adlakha (2014) and Cook (2006), but dissimilar to those of Kumar and Muniandy (2012). Regarding the qualification of the principals, the finding is similar to the finding of Adlakha (2014) which showed insignificant difference across the educational qualifications of the leaders. However, it contradicts with the findings of Kumar and Muniandy (2012) who had found improved emotional intelligence with the increase in academic qualification.

Nepali institutional school principals are effective in their leadership performance as the "students' score on the achievement test indicates the principals' effectiveness" (Nahavandi, 2008). This finding is similar to many empirical studies carried out by the researchers like Joshi (2017), Farahbakhsh (2012), Ying and Tzu Ting (2012), Shahzad and others (2011), Labbaf and others (2011), Assanova and McGuire (2009), Cook (2006), and Hartog and others (1997). Cook's (2006) and Hebert's (2010) studies indicated that emotional intelligence had a positive effect on leadership performance. Hence, EI of the principals can be an impactful predictor of the performance in Nepali School context. 
In overall perception of teachers towards principals' EI, the majority of the teachers agreed that the principals had high level of EI. It was similar in all types of principals with their different demographic characteristics. The findings of this study indicated that the school principals are emotionally intelligent and effective in the schools' academic performance.

\section{Conclusion}

In Nepali institutional schools, the principals, as perceived by their teachers, practice emotionally intelligent behaviours irrespective of their gender, age, experience, qualification and training status. They practice self-awareness, self-regulation, motivation, empathy and social skills effectively. Goleman's Mixed Model of EI explains the effectiveness of the principals' leadership in Nepali institutional schools. In the context of Nepali institutional schools, this study has established the reality that the higher the emotionally intelligent leadership of a leader, the greater is the effectiveness of the leadership performance. This idea can lead us to conclude that leadership performance in schools can be enhanced by developing emotional intelligence in principals' leadership. Further, the knowledge from this study can inform the school principals how their leadership can be made effective. The practitioners like principals or other school leaders can get insights from the dynamics of emotional intelligence that can be useful to improve the schools' performance.

\section{References}

Adlakha, Yogita K. (2014). Understanding the emotional intelligence of teachers with respect to select demographic variables. A Journal of Radix International Educational and Research Consortium, 3(6), pp. 1-13.

Albaum, Gerald. (1997). The Likert scale revisited: An alternate version. Journal of the Market Research Society, 39(2), 331-332.

Assanova, Maiya; and McGuire, Michael. (2009). Applicability analysis of the emotional intelligence theory, 3(1). Retrieved from http://citeseerx.ist. psu.edu/ viewdoc/download? doi=10.1.1.472.8431

Barbuto, John E.; Fritz, Susan M.; Matkin, Gina S.; and Marx, David B. (2007). Effects of gender, education, and age upon leaders' use of influence tactics and full range leadership behaviors. Sex Roles, 56(1-2), pp. 71-83.

Cherniss, Cary; and Goleman, Daniel (Eds.). (2001). The emotionally intelligent work place. San Francisco: Jossy Bass. 
Effect of Principals' Emotional Intelligence on Schools' Academic Performance...

Cochran, William Gemmell. (1977). Sampling techniques (3rd ed.). New York: John Wiley and Sons.

Cohen, Louis; Manion, Lawrence; and Morrison, Keith. (2007). Research methods in education. (6 ${ }^{\text {th }}$ ed.). NY: Rutledge Publication.

Cook, Charles Roy. (2006). Effect of emotional intelligence on principals' leadership performance. (Unpublished doctoral dissertation). Montana State University, USA.

Creswell, John W.; and Plano Clark, Vicki L. (2011). Designing and conducting mixed methods research ( $2^{\text {nd }}$ ed. $)$. New Delhi: Sage.

Creswell, John W. (2013). Educational research: Planning, conducting and evaluating quantitative and qualitative research ( $4^{\text {th }}$ ed.). Delhi: PHI Learning.

Farahbakhsh, Saeid. (2012). The role of emotional intelligence in increasing quality of work life in school principals. Procedia - Social and Behavioral Sciences, 46, pp. 31-35.

Fariselli, Lorenzo; Ghini, Massimiliano; and Freedman, Joshua. (2006). Age and emotional intelligence. Retrieved from https://www. 6seconds. org/sei/media/WP_EQ_and_Age. pdf.

Goleman, Daniel. (2000). Leadership that gets results. Harvard Business Review, 78(2), pp. 4-17.

Goleman, Daniel. (2004). What makes a leader? Harvard Business Review, 82(1), pp. 82-91.

Government of Nepal (GON). (2016). Education act, 1971 ( $8^{\text {th }}$ amendment, 2016). Kathmandu: Author.

Government of Nepal (GON). (2016). Education regulations, 2071 BS $\left(8^{\text {th }}\right.$ amendment). Kathmandu: Author.

Grunes, Paul. (2011). An examination of the relationship between emotional intelligence, leadership styles and perceived leadership outcomes in Australian educational institutions (Unpublished doctoral dissertation). School of Management, Faculty of Business, Qeensland University, Australia.

Hariri, Hasan. (2011). Leadership styles, decision -making styles, and teacher job satisfaction: Indoesian school context (Unpublished doctoral dissertation). James Cook University, Australia.

Harkness, Janet A. (2003). Questionnaire translation. In Harkness, J. F.; 
Effect of Principals' Emotional Intelligence on Schools' Academic Performance...

Vijer, Van de; and Moher, P. (Eds.), Cross cultural survey methods, pp. 35-56. London: John Wiley and Sons.

Hartog, Deanne N. Den; Muijen, Jaap J. Van; and Koopman, Paul L. (1997). Transactional versus transformational leadership: An analysis of the MLQ. Organizational Psychology, 70, pp. 19-34.

Hebert, Elizabeth B. (2010). The relationship between emotional intelligence, transformational leadership, and effectiveness in school principals. (Unpublished doctoral dissertation). Georgia State University, Atlanta.

Joshi, Priyadarshani. (2017). Identifying and investigating the "best" schools: A network-based analysis on Nepal's public education system. A Journal of Comparative and International Education, pp. 1-27.

Kumar, Jaya Amantha; and Muniandy, Balakrishnan. (2012). The influence of demographic profiles on emotional intelligence: A study on polytechnic lecturers in Malaysia. International Online Journal of Educational Sciences, 4(1), pp. 62-70.

Kumar, Sanjay (2014). Establishing linkages between emotional intelligence and transformational leadership. Industrial Psychiatry Journal, 23(1), 1-3. doi: 10.4103/0972-6748.144934.

Labbaf, Hasan; Ansari, Mohammad Esmaeil; and Masoudi, Masoomeh (2011). The impact of the emotional intelligence on dimensions of learning organization: The case of Isfahan University. Interdisciplinary Journal of Contemporary Research in Business, 2(5), pp. 536-545.

McPheat, Sean. (2010). Emotional intelligence: MDT training. London, UK: Book Boon.

Nahavandi, Afsaneh. (2008). The art and science of leadership (5 $5^{\text {th }}$ ed.). New York, NY: Prentice Hall.

Northouse, Peter G. (2010). Leadership: Theory and practice (5 $5^{\text {th }}$ ed.). New Delhi: Sage.

Northouse, Peter G. (2013). Leadership: Theory and practice $\left(6^{\text {th }}\right.$ ed.). New Delhi: Sage.

Rahim, M. Afzalur; and Psenicka, Clement. (2002). A model of emotional intelligence and conflict management strategies: A study in seven countries. The International Journal of Organizational Analysis, 10(4), pp. 302-326.

Shahhosseini, Mohammad; Silong, Abu Daud; and Ismaill, Iismi Arif. 
Effect of Principals' Emotional Intelligence on Schools' Academic Performance...

(2013). Relationship between transactional, transformational leadership styles, emotional intelligence and job performance. International Refereed Research Journal 4(1), 15-25. Retrieved from www.researchersworld. com

Shahzad, Khurram; Sarmad, Muhammad; Abbas, Muhammad; and Khan, Muhammad Abbas. (2011). Impact of emotional intelligence (EI) on employee's performance in telecom sector of Pakistan. African Journal of Business Management, 5(4), pp. 1225-1231.

Shipley, Natalie L.; Jackson, Mary Jo; and Segrest, Sharon L. (2010). The effects of emotional intelligence, age, work experience, and academic performance. Research in Higher Education Journal, 9(1), pp. 1-18.

Singh, Dalip. (2003). Emotional intelligence at work (2 ${ }^{\text {nd }}$ ed.). New Delhi: Sage.

Weinberger, Lisa Ann. (2003). An examination of the relationship between emotional intelligence, leadership style and perceived leadership effectiveness. Retrieved From http://citeseerx.ist.psu.edu/viewdoc/ download? doi=10.1.1.543. 6596andrep=replandtype=pdf

Ying, Cheah Yeh; and Tzu Ting, Shirley Ken. (2012). Emotional intelligence and transformational leadership outcomes: Insights from a Malaysian perspective. World Journal of Social Sciences, 2(2), pp. 151 -160. 